\title{
Indigenising Mathematics Mediations in South African High Schools: Applying Ethnomathematics Experiences in Teaching and Learning
}

\author{
Jabulani Nyoni \\ Department of Educational Leadership and Management, University of South Africa \\ Email: nyonij@unisa.ac.za
}

\author{
Doi:10.5901/mjss.2014.v5n15p327
}

\begin{abstract}
This article applies anthropological theory in exploring how Mathematics teachers imbed indigenous epistemologies in the teaching of pure Mathematics in high schools in South Africa. I spent two months staying in one of the Venda communities sharing at times food and other amenities with the three boys, at the same time collecting data and understanding cultural practices. I observed the participants on a daily basis, playing a mathematical game called "mutoga" in their local language. I also joined them in class where they were taught Mathematics at school. Findings seem to indicate that ethnomathematics epistemologies can successfully be embedded in the teaching of pure Mathematics in South African high schools. I therefore argue that the use of indigenous mediation experiences must assume culturally responsive pedagogy to open up the curriculum and assessment practices to allow for different ways of knowing and being. Initially, a generic argument for the inclusion of indigenous content within the Mathematics curriculum is suggested. Secondly, several exemplar scenarios of teaching praxis including indigenous content are discussed. Finally, evidence on the utility of such exemplar scenarios for students in learning about indigenous peoples and key processes and skills for working with indigenous communities from student feedback are discussed.
\end{abstract}

Keywords: First nation, indigenous epistemologies, mutoga (ethnomathematical game), pedagogical content knowledge (PCK)

\section{Introduction}

Shivji's account deviates from the familiar narrative that charts colonialism-decolonisation-liberation on a historicalprogressivist continuum with an ongoing imperative for "transformation" to "purge" higher education from the last vestiges of colonialism. Shivji's account inserts some traditions of African universities concluded in national triumphalism: the fight for academic freedom in conjunction with the right to self-determination, undermined by neoliberalism and globalisation, which brought the return of the "colonised mind".

Imperialism and capitalism masquerading as globalisation and free market set the rules of the game. Universities were dubbed white elephants as the colonised Africans did not need thinkers, asserted their erstwhile benefactors. Africans only needed storekeepers and bank tellers and computer operators and marketing managers, who could be trained in vocational schools.

The so-called "traditional Africa" receives a boost with the assertion that local knowledge systems, values, and identities have been suppressed by colonialism and apartheid. They need to be freed from these shackles; it is argued or implied, to be fully rehabilitated, reconstituted, and recognised as aspects of "African epistemology" and "African identity." In tandem with such "reconstitution," more African students and staff need to be brought into universities. It is assumed that this will have a democratising effect and enhance a transformative vision. To the extent that African intellectuals transcended the idea of a "national culture" to embrace a Pan-African vision as a form of universalism and inclusive citizenship, they had their hopes dashed by the national chauvinism of postcolonial elites, which was inimical to expressions of independent critical thought. Ali Mazrui's point is instructive in this respect: "The decline of intellectualism and the decline of Pan-Africanism unfolded almost simultaneously." Fanon describes this "Africanity" as a "universal standpoint" and understands it as a necessary counterpoint to "national culture".

Much has been written over the years about complications African learners experience when learning science (see Ogawa 1989; Ogunniyi 1988, 2007; Jegede 1989; Jegede and Okebukola 1989; Jegede and Fraser 1990; Okebukola and Jegede 1990; Jegede 1996). Despite this body of literature that has been produced and the fact that indigenous knowledge systems reside among the majority of South Africans, the topic has not been given the attention it deserves.

The SA Institute of Race Relations (SAIRR) revealed that 84 high schools didn't offer Mathematics for the Further Education and Training (FET) phase - grades 10 to 12 -"primarily as a result of a shortage of suitably qualified pure 
mathematics teachers". Anecdotal evidence points to the fact that most pupils choose their subjects based on what they think they can pass in Grade 12, without realising that many courses at university will not accept candidates with only Maths literacy.

\section{The Philosophy and Cultural Nature of Ethnomathematics}

The core of any debate about the cultural nature of ethnomathematics will ultimately lead to an examination of the nature of Mathematics itself. One of the oldest and most controversial topics in this area is whether ethnomathematics is internal or external, tracing back to the arguments of Plato, an externalist, and Aristotle, an internalist. On the one hand, internalists such as Bishop, Stigler and Baranes, believe Mathematics to be a cultural product. On the other hand, externalists, like Barrow, Chevallard and Penrose, see mathematics as culture-free, and tend to be major critics of ethnomathematics. With disputes about the nature of Mathematics, come questions about the nature of ethnomathematics, and the question of whether ethnomathematics is part of Mathematics or not. Barton, who has offered the core of research about ethnomathematics and philosophy, asks whether "ethnomathematics is a precursor, parallel body of knowledge or precolonized body of knowledge" to Mathematics and if it is even possible for us to identify all types of Mathematics based on a Western-epistemological foundation. I

\section{Anthropological Theory}

Anthropological theory focuses on folklore in non-literate cultures, like African and indigenous cultures. Many anthropologists believe these folkloric accounts form ethnographies of individual cultures. Anthropologically, folklore functions as a mediator for political decisions, validates conduct, releases emotions, and much more in cultural context. Also, anthropological theory applies content, function and style to the analytical processes of folklore tales.

As scholars we are politically and intellectually engaged in demonstrating how critical indigenous studies as a mode of analysis can offer accounts of the contemporary world of indigenous peoples that centre our ways of knowing and theorising. Our writing is challenging and innovative, engaging theory to philosophise and apply to questions that concern us and our communities. Unlike many cultures whose history has been documented, South Africa's rich and colourful indigenous knowledge (IK) relies on the spoken word - a tradition carried over from generation to generation for millennia. However, as communities become more sophisticated and urbanised, much of this IK is lost, misappropriated or misused. The traditional leader of Bakgatla-Ba-Kgafela Tribal Authority (BBKTA), Kgosi Nyalala Pilane, said the tribal authority was committed to ensuring that their shared cultural heritage, traditions and value systems were upheld for the benefit of current and future generations.

The erosion of the African indigenous knowledge base is largely associated with the absence of mechanisms to ensure that the knowledge and related practices are passed on from one generation to the next. Often old generations are dying without endowing new ones with the wealth of information and skills on the use and management of African ecological and agricultural systems. This threatens the future cultural wellbeing of African communities. Orality theories to Africans endeavour to teach and tell informative tales through word of mouth.

\section{Language as a Political and Economic Power Tool}

This proposed project aims at promoting education on African indigenous knowledge systems in schools and institutions of higher learning. It will facilitate the integration of indigenous knowledge issues into curriculums and related teaching methodologies.

Specific actions to further develop and implement this project will include:

- reviewing the indigenous knowledge content of current curricula of African education systems, and identification of international good practices of integration of indigenous knowledge issues into formal education;

- African workshops for educational systems to consider proposals on how best to integrate indigenous knowledge into the curricula and teaching practices. The workshops will focus on and be guided by international good practices; and

- development and promotion of an African body of methodology and guidelines for integrating indigenous knowledge systems into formal education and training.

Mosimege and Lebeta (2000:336-341) reported on the indigenous mathematical knowledge as used by the 
inhabitants of the village. They found extensive use of a variety of mathematical concepts in the following grass artefacts: (i) traditional baskets (ii) traditional hats and (iii) miscellaneous items (Mothotho (strainer), plaited rope used for binding, etc).

\section{Multilingualism in Africa}

Teaching in Africa over the years has become more complex, particularly so after the demise of colonialism. Crossborder migration, globalisation and the emergence of urbanisation meant that different cultures have come together, thereby creating new cultural identities and language transformation in society in general and in schools in particular. Literally students in African schools are in the majority of cases multilingual due to the introduction of English, Portuguese or French as foreign official languages as were used by colonial masters then. The term "foreign" but "official" languages, with respect to the ex-colonial languages, are at times unsatisfactory. On the one hand, from the perspective of many African learners, ex-colonial languages, though they may have become official, are foreign. From the social perspective, on the other hand, they are no longer foreign languages as they have acquired official status and in some African countries have been present for over 100 years.

Multilingualism in the education of an African child usually means the mother tongue plus second or more official languages as medium of instruction. In South Africa bilingual education is understood as mother-tongue used as medium of instruction (L1 medium) throughout school plus a second language taught as a subject to a high level of proficiency. The use of the term in this way has been transported to many countries in Africa where programmes may be referred to as bilingual even though there is a minimal L1 medium in place.

\section{Indigenousness and the Teaching of Mathematics}

There is currently a global initiative of maintaining world views, languages, and environments of which science education can be a part (McKinley, 2007). Also, science education needs to consider the indigenous communities themselves and pay attention to the needs of the people. Because of the complex relationships that are reflected in the literature on indigenous students, which highlight the historical and current effects of colonisation, including changes to their language and culture, indigenous studies are grounded in political and moral bases. David Clark (2004) argued that indigenous studies are about "restoring well-being to our nations" (p. 230). Well-being for indigenous students comes from an approach that involves social, economic, and cultural development and a "strong sense of identity as indigenous" (McKinley, 2007, p. 221). However, in order to for indigenous knowledge systems to continue, we need people with the ability to embrace indigenous ways and science. To accomplish this we need to not only create the space where that can happen but learn through their experiences how this can be done. The reality of the current situation is that most indigenous students are in cross-cultural classrooms where the teacher is from a different cultural group and often does not speak the same language, and has different knowledge systems than the students (McKinley, 2007).

Ideologies influence power and language plays an important role in constructing and deconstructing ideologies. "Ideology" is a term developed in the Marxist tradition that describes how cultures are structured in ways that enable the group holding power to have the maximum control with the minimum conflict (Lye, 2007). It can be defined as a set of beliefs, perceptions, assumptions, and values that provide members of a group with an understanding and explanation of their world (Beard, 2005:118). Ideologies involve communication of ideas and therefore, language plays a central role in constructing and maintaining discrimination and oppression. In fact, it must be emphasised that language can never be "neutral as it bridges our personal and social worlds (Van Dijk, 1988).

\section{Pluriversality of Indigenousness}

Here African philosophy, in certain respects, has remained close to its ultimate rootedness in the everyday experience of people living in historic communities (be they agricultural villages, cattle posts, royal capitals or migratory bands). They are seeking to conceptualise and to understand the world around them and to survive in the face of both outside threats (of a political, military as well as environmental nature) and of the incessant internal centrifugal tendencies inherent in any human social group. However, Malatest et al. (2004, p. 34) argue:

[i]t's believed that Aboriginal students in science based professions, especially health and natural resources, will increase as self-government increases ... Herman Michell of the First Nations University of Canada states that meaningful self-government can only be exercised by a balanced pool of educated Aboriginal resource people. Including IKs [sic] in tertiary science education without challenging the dominance of Western science and embracing genuine ontological 
pluralism is problematic for Indigenous [sic] peoples as the legitimacy of Indigenous knowledge systems cannot be recognized. This inability precludes any meaningful negotiation of how the knowledge domain of science education is occupied. Rose (1999, p. 182-3) stresses the importance of educators remaining vigilant and discerning about possible entrenched colonial practices that are easily overlooked:

This embeddedness may conceal, naturalize, or marginalize continuing colonizing practices ... Furthermore, practices of colonization are so institutionalised in political and bureaucratic structures and policies, that they are almost unnoticed.

\section{Pedagogical Content Knowledge (PCK)}

The notion of PCK was first conceptualised by Shulman $(1986,1987)$ and has become a widely used concept in education as a vehicle to understand how teachers organise and conceptualise their teaching. Shulman refers to PCK as "the most powerful analogies, illustrations, examples, explanations and demonstrations". In other words, the ways of representing and formulating the subject matter that makes it comprehensible for others (Shulman 1987, 9). According to Shulman, PCK involves how the subject matter of a particular discipline is transformed for communication with learners. It includes recognition of what makes specific topics difficult to learn, as well as the conceptions students bring to the learning of those concepts. Since its introduction, PCK has been interpreted in a variety of ways by educators. For example, Loughran, Gunstone, Berry, Milroy and Mulhall (2000) view the PCK of teachers as a mixture of interacting elements (views of learning, views of teaching, understanding of content, understanding of students, knowledge and practice of children's conceptions, time, context, views of scientific knowledge, pedagogical practice, decision making, reflection, and explicit versus tacit knowledge of practice/beliefs/ideas), that combine to give insight into PCK. Grossman (1990) views PCK as being composed of four distinct components: knowledge and beliefs for teaching subject matter; knowledge of students' understanding, conceptions and misconceptions of particular topics in a discipline; knowledge of curriculum; and knowledge of instructional strategies and representations.

Hutchings and Shulman (1999) have extended the notion of pedagogical content knowledge into a scholarship of teaching, emphasising the need for faculty understanding and knowledge, acquired through inquiry into teaching, to be shared in a public format for review and scrutiny.

In understanding teachers' reading literacy pedagogical content knowledge (PCK) in this study, we used a model proposed by Magnusson, Krajcik and Borko (1999) that consists of five distinct yet interrelated components:

1. Orientations to teaching: these are ways of viewing how a subject should be taught and how these views guide instructional decision making. Many instructors' choices of instructional approaches may reflect several distinct orientations (induction, inquiry, direct instruction, problem based, simulations), while their reasons for adopting particular approaches are indicative of an instructor's orientation. According to Magnusson et al (1999), orientations to teaching influence the development of other components of PCK (see below) and it, in turn, is influenced by the other components.

2. Knowledge of curriculum: this includes an understanding of curriculum goals and outcomes in particular courses and across courses and programs. Also, this category involves an awareness of the curriculum resources available to support instruction.

3. Knowledge of student understanding: this includes instructors' insight into what prerequisite knowledge, abilities and skills students need to learn particular topics, as well as an understanding of how students vary in their approaches to learning particular topics. A second area targeted in this category is instructors' knowledge of concepts and ideas that are difficult for students to learn.

4. Knowledge of assessment: this includes instructors' understanding of which aspects of students' learning are important to assess within a learning episode or unit, as well as the methods of assessment that are appropriate for determining the learning that has occurred.

5. Knowledge of instructional strategies: this includes instructors' understanding of which instructional strategies may be used in a discipline generally, as well as specific strategies that would be useful to adopt when addressing particular aspects.

\section{Issues of Methodology}

Participant observation is a fundamental method of research used in cultural anthropology. It involves a researcher, or researchers, living within a given culture for an extended period of time, to take part in its daily life in all its richness and diversity. The anthropologist in such an approach tries to experience a culture "from within", as a person native to that 
culture might do. Ethnography and ethnology are interrelated in a complex fashion. The deductive scientific method dictates that research must be organised to address a theoretical hypothesis that is derived from prior reasoning. This requirement creates an anthropological dilemma, however, since an ethnographer must understand his/her observations in terms of their meanings within a particular cultural context, which may substantially depart from the theoretical system chosen for interpretation. There are accordingly two ethnographic styles:

1. the deductive, or problem oriented, approach, which narrows investigation in terms of issues and principles identified as significant within anthropological theory

2. the inductive approach, which identifies research problems and builds explanations from the field experience per se. Inductive approaches have been more characteristic of the older schools of anthropology that developed between the start of the century and World War II. They have resulted in fairly general ethnographic descriptions. Problem oriented approaches are typical of current anthropological research and tend to focus on specialised subject matter, such as subsistence techniques, economic transactions, or religious rituals. Anthropologists must still take general ethnography and local meaning systems into account, however, and must be open to modifying their research directions and theoretical assumptions if they prove to be inapplicable or problematic.

After the initial orientation or entry period, which took three months, I followed a more systematic programme of formal interviews involving questions related to research hypotheses and specialised topics. Several different methods of selecting informants were possible. A few key participants (between 2 and 5) were selected for in-depth sessions, since the investigation of cultural patterns usually calls for lengthy and repeated open-ended interviews. Selection of such a small number did not allow for strict assurance of a representative sample, so I carefully chose subjects who were well informed and reliable. As an ethnographic researcher I also trained participants to systematically report cultural data and recognise significant cultural elements and interconnections as the interview sequences unfolded. I finally settled for three participants who came from the same village; spoke the same language, shared experiences and interests, et cetera. The purposively selected participants are listed in table 1.

Table 1: Participant pseudonym and educational functions

\begin{tabular}{|c|c|}
\hline Pseudonym & Educational roles \\
\hline Mafenya & Mathematics teacher \\
\hline Chikopa & Mathematics student \\
\hline Ndefuwo & Mathematics student \\
\hline Nyeledzi & Mathematics student \\
\hline Pfiwa & School principal \\
\hline
\end{tabular}

\section{Ethical Considerations}

To our resource persons or research subjects we owe full and timely disclosure of the objectives, methods and sponsorship of our activities. We should recognise the rights of resource persons, whether individuals or groups, to receive recognition for their contributions or to remain anonymous if they so desire or to decline participation altogether. These persons should be informed of our commitment to the principle of confidentiality throughout the design of research or other activities involving resource persons and should thoroughly investigate and understand all of the limitations on our claims of confidentiality and disclosure.

\section{Discussion of Findings, Recommendations and Conclusion}

Indigenous inquiry skills are used to explore knowledge uniquely associated with inquiry into and with learning of mathematics through the application of ethno-mathematics experiences and games. These skills are associated with:

- reciprocating knowledge

- deep listening

- reflecting and revisiting

- respectful interactions

- managing and recognising community protocols.

Indigenous principles such as community responsibility, lifelong learning, cross-generational resonance and revisiting inform the development of these skills and are invariably becoming important tools and avenues for teaching 
and learning of mathematics in formal high schools.

The application of an anthropological theory in my study yielded synoptic findings herewith discussed. One will quickly acknowledge that in all levels of schooling, however, indigenous peoples continue to be significantly underrepresented, compared to non-indigenous students -and South Africa is no exception. However, indigenising mathematics curriculums is a complex and contested process that should not be mistaken as a simple addition of "indigenous components to the mix". Such an exercise risks the appropriation and incorporation of IKs into a Western science education framework.

In the interview with the Vhavenda learners, they indicated that knowledge of working with pebbles is passed on by grandparents to their children. This is one way of ensuring that indigenous knowledge in the communities does not become extinct but is used appropriately to link what happens within mathematics classrooms and ethnomathematics activities outside the classrooms. For example, to start with, table 2 shows how counting is done in the Tshivenda community and these numbers are used throughout whenever the game of mutoga is played.

Table 2: Counting in base ten in the local language

\begin{tabular}{|c|c|c|}
\hline Number & Word & Is derived from a phrase meaning \\
\hline 1 & nthihi & one (1) \\
\hline 2 & mbili & two (2) \\
\hline 3 & raru & three (3) \\
\hline 4 & ina & four (4) \\
\hline 5 & thanu & five (5) \\
\hline 6 & rathi & six (6) \\
\hline 7 & sumbe & seven (7) \\
\hline 8 & malo & eight (8) \\
\hline 9 & tahe & nine (9) \\
\hline 10 & fumi & Ten (10) \\
\hline
\end{tabular}

Source: Adapted from Rambane, DT and Mashige, MC, Indigenous Mathematical game, Mutoga (Tshivenda name)

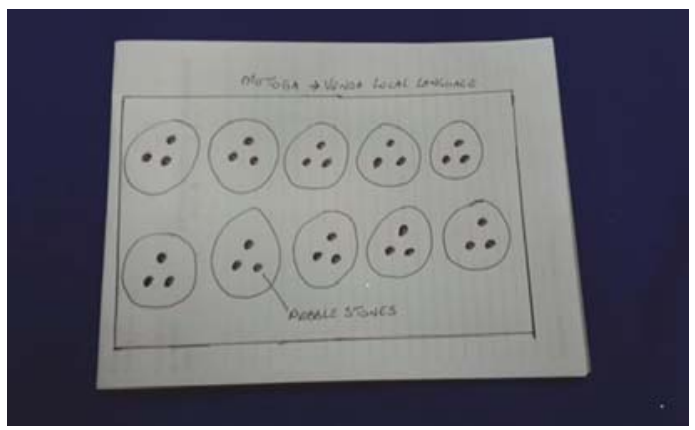

Many "mathematical" ideas and activities in African cultures are not explicitly mathematical. They are often intertwined with art, craft, riddles, games, graphic systems, and other traditions. The mathematics is often "hidden". How may this "hidden" knowledge be uncovered? As some traditions are nowadays (becoming) obsolete, this "uncovering" often also means a tentative reconstruction of knowledge as it existed in the past.

Today's existing African educational system is "unadapted and elitist" and "favours foreign consumption without generating a culture that is both compatible with the original civilization and truly promising" (Ki-Zerbo, 1990, 4; cf. El-Tom on mathematics education and the selection of élites, 1984, 3).

What type of mathematics pedagogy must African students negotiate to be successful in school? Typical mathematics pedagogy emphasises whole-class instruction, with teachers describing a technique to solve a problem and students listening. The principles that undergird the Africentric philosophy of education were articulated by Woodson in The Mis-Education of the Negro (1933/1990). Woodson's major thesis argues that African Americans have been educated away from their culture and traditions and have associated more with European values and traditions. Woodson (1933/1990) stated: 
When a Negro has finished his [sic] education in our schools, then, he has been equipped to begin the life of an Americanized or Europeanized white man, but before he steps from the threshold of his alma mater he is told by his teachers that he must go back to his own people from whom he has been estranged by a vision of ideals which in his disillusionment he will realize that he cannot attain ... (pp. 5-6)

Asante (1987) argues that all analysis is culturally centered and develops from ideological assumptions; this is the most important lesson from modern intellectual history. The Afrocentric method looks to construct a world-view of communication - written and oral - of oppressed people (Asante, 1987).

\subsection{Subconscious deployment of ethnomathematics in classroom situations}

In accordance with D'Ambrosio's (1977) assertion that the definition of ethnomathematics should in essence include peoples' culture, cultural identities and practices among others, it therefore becomes rather intricate for the common ground for ethnomathematics. However, Wikipedia proffers a near encapsulating definition thus, "the study of the relationship between mathematics and culture often associated with 'cultures without written expression'. It may also be defined as "the mathematics which is practised among identifiable cultural groups", if I may add. It refers to a broad cluster of ideas ranging from distinct numerical and mathematical systems to multicultural mathematics education. The goal of ethnomathematics is to contribute both to the understanding of culture and the understanding of mathematics, and mainly to lead to an appreciation of the connections between the two. The following narrative from my observation in the field was framed within the context of the analysis of the connections between culture and mathematics.

\subsection{Chikopa (matric student at $X$ secondary school) (Age: 18 years)}

In the field of mathematics education, some scholars have theorised about culturally relevant approaches to mathematics education. In class Chikopa would sit next to his friend and begin exchanging notes written in Tshivenda on how the game progressed the previous day. For example, Stanic (1991) contends an important step toward equity in mathematics education is to question the epistemological foundation of the field. He argues that, taken together, culture practice theory and critical theory provide the foundation for a reform and research agenda in mathematics education.

In the Australian curriculum, for example, students learn how to behave ethically as they identify and investigate the nature of ethical concepts, values, character traits and principles, and understand how reasoning can assist ethical judgment. Ethical behaviour involves students in building a strong personal and socially oriented ethical outlook that helps them to manage context, conflict and uncertainty, and develop an awareness of the influence that their values and behaviour have on others. Chikopa was observed in class consulting class mates in his mother tongue on how to go about solving a particular mathematical problem. The thoughts on and taping of experiences were translated from the mother tongue into English and that proved very difficult.

\subsection{Ndefuwo (matric student at $X$ secondary school) (Age: 17 years)}

This cultural divide between school and community is a major factor causing the persistent gap between academic achievements, especially if we think of schools as part of the community to which they belong. By linking culture and the curriculum, teachers nurture the love for mathematics outside the classroom in order to assist what happens inside the classroom (Wyk, 2009).

In the Australian curriculum, students become literate as they develop the knowledge, skills and dispositions to interpret and use language confidently for learning and communicating in and out of school and for participating effectively in society. Literacy involves students in listening to, reading, viewing, speaking, writing and creating oral, print, visual and digital texts, and using and modifying language for different purposes in a range of contexts. Ndefuwo looked shy and removed from class activities despite the probing by the teacher. On close observation, it appeared the problem was the English language: "I barely understand what these questions demand from us. Usually my friend Chikopa tries to explain to me what these questions demand but I always get the answers wrong. I would be better to be taught in Tshivenda". Translated. Crucially the findings indicate that learners would learn pure Mathematics better if they were taught in their mother tongue. After all, great mathematicians did it in their mother tongue.

\subsection{Nyeledzi (matric student at $X$ secondary school) (Age: 18 years)}

Students develop capability in critical and creative thinking as they learn to generate and evaluate knowledge, clarify 
concepts and ideas, seek possibilities, consider alternatives and solve problems. Critical and creative thinking are integral to activities that require students to think broadly and deeply using skills, behaviours and dispositions such as reason, logic, resourcefulness, imagination and innovation in all learning areas at school and in their lives beyond school. On observation Nyeledzi appeared to be the leader in his group. The group activities entailed solving simultaneous equations by using matrices:

$$
\text { Solve the simultaneous equation: } \quad \begin{aligned}
& 5 x-2 y=16 \\
& 7 x+6 y=-4
\end{aligned}
$$

The educator endeavoured to explain using the language of instruction of which he experienced difficulties in the use of the language. It was evident that the educator struggled with the language later on to give clearly articulated instructions. The language of power, English, made it very difficult for both the educator and the learner to master mathematical concepts. One would proffer that had both the educator and the learner been given the latitude to use their mother tongue, lessons were going to be meaningful and enjoyable.

\section{Conclusion}

Many Vhavenda people see the traditional indigenous games as a strong indicator that their culture can survive. In this way traditional games are not only helping Vhavenda youth to get physically fit but also inspiring older members of the indigenous community. Some games involved only men and boys, even old men, while in other games everyone was allowed to participate. Through the use of IKs in the Australian curriculum for example, students become numerate as they develop the knowledge and skills to use ethnomathematics confidently across all learning areas at school and in their lives beyond school and such initiatives are missing in South African high schools. Numeracy involves students recognising and understanding the role of ethnomathematics in the world and having the dispositions and capacities to use ethnomathematical knowledge and skills purposefully but provided they are allowed to express their experiences in their mother tongue.

\section{References}

Asante, M. (1987). The Afrocentric idea. Philadelphia: Temple University Press.

D'Ambrosio. (1997). "Foreword", Ethnomathematics, p. xv and xx. ISBN 0-7914-3352-8.

El Tom, M. (1984). The role of Third World University Mathematics institutions in promoting mathematics, paper presented at the 5th International Congress on Mathematical Education, Adelaide (mimeo) http://mg.co.za/article/2008-09-09-maths-with-amission\#disqus_thread (accessed on 02 May 2011).

Hutchings, P., \& Shulman, L. S. (1999). "The scholarship of teaching: New elaborations, new developments." Change September/October 1999: 10-15.

Jegede, O.J. (1989). Mathematical Requirements of the West African School Certificate Biology 1976 to 1985. Journal of the Science Teachers' Association of Nigeria, 26 (1), 12-23.

Jegede, O.J. (1996). In support of culturally and individually responsive science education graduate programs for international students: comment on Lunetta and van den Berg. Science Education, 80(1), 101-104.

Jegede, O.J. \& Fraser, B.J. (1990). The Effects of Instruction on Science Students' Socio-Cultural Attitudes and Achievement. Singapore Journal of Education, 1(1), 12-18.

Jegede, O.J. \& Okebukola, P.A.O. (1989). Some Socio-Cultural Factors Militating against Drift Towards Science and Technology in Secondary Schools. Research in Science and Technological Education, 7(2), 141-151.

Ki-Zerbo, J., ed. (1990). Educate or perish. Dakar-Abidjan, UNESCO-UNICEF.

Loughran, J.J., Gunstone, R.F., Berry, A., Milroy, P., \& Mulhall, P. (2000, April). Science cases in action: Developing an understanding of science teachers' pedagogical content knowledge. Paper presented at the annual meeting of the National Association for Research in Science Teaching, New Orleans, LA, USA.

Lye, J. (2007): Ideology [accessed February 13, 2011]

http://www.brocku.ca/english/jlye/ideology.html

Magnusson, S., Krajcik, J. \& Borko, H. (1999) Secondary teachers' knowledge and beliefs about subject matter and their impact on instruction In: Gess-Newsome, J. and Lederman, N.G. Eds (1999) Examining Pedagogical Content Knowledge Dordrecht: Kluwer Academic Publishers p $95-132$

Malatest and Associates Ltd. (2004). Aboriginal peoples and post-secondary education: What educators have learned. Montreal: Canadian Millennium Scholarship Foundation.

McKinley, E. (2007). Postcolonialism, indigenous students, and science education. In S. K. Abell \& N. G. Lederman (Eds.), Handbook on Science Education (pp. 199-226). Mahwah: NJ: Lawrence Erlbaum Associates, Inc.

Mosimege, M. and Lebeta, V. (2000). An ethnographic study of mathematical concepts at the Basotho Cultural Village. In: S. Mahlomaholo, M. Nkoane and K. Smit (eds). Proceedings of the 8th annual conference of the Southern African Association for 
Research in Mathematics and Science Education. University of Port Elizabeth.

Nkopodi, N., \& Mosimege, M. (2009). Incorporating the indigenous game of morabaraba in the learning of Mathematics. South African Journal of Education 29:377-392.

Ogawa, M. (1989). Beyond the tacit framework of 'science' and 'science education' among science educators. International Journal of Science Education, 11, 247-250.

Ogunniyi, M. B. (2007). Teachers' stances and practical arguments regarding a science-indigenous knowledge curriculum: Part 1. International Journal of Science Education, 29, 963-986.

Ogunniyi, M. B. (1988). Adapting western science to traditional African culture. International Journal of Science Education, 10, 1-9.

Okebukola, P.A.O. \& Jegede, O.J. (1990). Eco-cultural Influences upon Students' Concept attainment in science. Journal of Research in Science Teaching, 27(7), 661-669.

Rambane, D.T. \& Mashige, M.C. (2007). The role of mathematics and scientific thought in Africa: A Renaissance perspective. International Journal of African Renaissance Studies 2(2):183 -199.

Rose, D. B. (1999). Indigenous ecologies and an ethic of connection. In N Low (ed.. Global ethics and environment (pp. 175-187). London: Routledge.

Stanic, G.M.A. (1991). Social inequality, cultural discontinuity, and equity in school mathematics. Peabody Journal of Education 6(6):5771.

Woodson, C.G. (1990). The mis-education of the Negro. Trenton, NJ: Africa World Press. (Original work published 1933).

Wyk, S. (2009). Mathematics with a Vision. [Online] Available: from http://mg.co.za/article/2008-09-09-maths-with-amission\#disqus_thread (May 02, 2011) 